\title{
CLEC3B is downregulated and inhibits proliferation in clear cell renal cell carcinoma
}

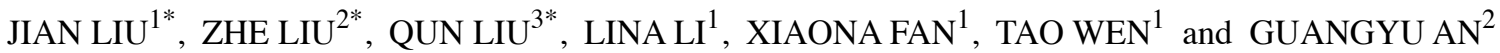 \\ ${ }^{1}$ Medical Research Center and ${ }^{2}$ Department of Oncology, Beijing Chao-Yang Hospital, \\ Capital Medical University, Beijing 100020; ${ }^{3}$ Department of Obstetrics and Gynecology, \\ Beijing Anzhen Hospital, Capital Medical University, Beijing 100029, P.R. China
}

Received February 23, 2018; Accepted July 19, 2018

DOI: $10.3892 /$ or.2018.6590

\begin{abstract}
Dysregulation of C-Type Lectin Domain Family 3 Member B (CLEC3B) in serum or tumor tissues has been reported in patients with various cancer types. However, the expression and function of CLEC3B in clear cell renal cell carcinoma (ccRCC) remain unknown. To examine the function of CLEC3B in ccRCC, The Cancer Genome Atlas (TCGA) and Gene Expression Omnibus (GEO) databases were examined to determine the expression of CLEC3B at the transcriptional level and it was demonstrated that CLEC3B mRNA was significantly downregulated in ccRCC compared with normal tissues $(\mathrm{P}<0.0001$ and $\mathrm{P}=0.0392$ in TCGA and GEO databases, respectively). The downregulation of CLEC3B was further validated at the protein level in $78.9 \%$ of ccRCCs by immunohistochemistry. To investigate the potential genetic mechanism for CLEC3B downregulation in ccRCC, copy number analysis was performed by profiling the copy number
\end{abstract}

Correspondence to: Professor Guangyu An, Department of Oncology, Beijing Chao-Yang Hospital, Capital Medical University, 8 Gong Ti Nan Lu, Beijing 100020, P.R. China

E-mail: anguangyu@hotmail.com

Professor Tao Wen, Medical Research Center, Beijing Chao-Yang Hospital, Capital Medical University, 8 Gong Ti Nan Lu, Beijing 100020, P.R. China

E-mail: wentao5281@163.com

"Contributed equally

Abbreviations: CLEC3B, C-Type Lectin Domain Family 3 Member B; CNV, copy number variation; TCGA, the Cancer Genome Atlas; KIRC, kidney renal clear cell carcinoma; GEO, Gene Expression Omnibus; ccRCC, clear cell renal cell carcinoma; VHL, von Hippel-Lindau Tumor Suppressor, pRCC, papillary renal cell carcinoma; OS, overall survival; DFS, disease-free survival; HR, hazard ratio; CI, confidence interval; RTCA, real-time cell analyzer system

Key words: C-Type Lectin Domain Family 3 Member B, downregulation, copy number loss, clear cell renal cell carcinoma, proliferation variation data from the TCGA project and it was revealed that the copy number loss of CLEC3B was prevalent in up to $88.1 \%$ of patients with ccRCC. CLEC3B genetic deletion was coupled with the well-known genetic loss of the von Hippel-Lindau tumor suppressor, which is a characteristic oncogenic event during ccRCC carcinogenesis. The downregulation of CLEC3B was associated with tumor progression and predicted unfavorable prognostic outcomes in the TCGA cohort. Real-time cell analyzer system technology revealed that CLEC3B inhibited the proliferation of ccRCC cell lines in vitro and that the mitogen-activated protein kinase pathway may contribute to this process. CLEC3B demonstrated substantial positive associations with proliferation inhibitors, but inverse associations with proliferation inducers and markers in two large ccRCC cohorts, suggesting that CLEC3B was able to identify ccRCCs with a lower proliferation capacity. In conclusion, the results of the present study propose that CLEC3B is a promising target for therapeutic intervention in ccRCC.

\section{Introduction}

Renal cell carcinoma (RCC) represents $>90 \%$ of all kidney and renal pelvis cancer cases and ranks among the 10 most common cancer types globally (1). There are 3 major histologic subtypes of RCC: Clear cell RCC (ccRCC), papillary RCC (pRCC) and chromophobe RCC. ccRCC accounts for $75-80 \%$ of all RCC cases and the majority of mortality cases from kidney cancer (2). Despite the availability of numerous types of treatments, $\sim 30 \%$ of patients with ccRCC eventually develop metastasis, resulting in high mortality rates (3).

Previous advances in high-throughput platforms to profile genome-wide changes have contributed substantially to improvements in the genomic and molecular characterization and treatment of ccRCC $(2,4,5)$. Genetic alterations in a number of genes, including von Hippel-Lindau tumor suppressor (VHL), polybromo 1, SET domain containing 2, BRCA1 associated protein 1, lysine demethylase 5C and mechanistic target of rapamycin kinase, are prevalent in ccRCC (6). Genetic loss of the tumor suppressor gene VHL, which was originally identified in von Hippel-Lindau disease, is the best recognized gene associated with the development of ccRCC. Loss of VHL, which is located at chromosome 3p25 and encodes phosphorylated (p-)VHL, is the characteristic 
genetic alteration of ccRCC and is believed to occur at a very early step in renal carcinogenesis (5). VHL inactivation increases the risk of developing ccRCC, whereas the restoration of VHL function in VHL-/- ccRCC cells is sufficient to inhibit tumorigenesis in vivo (7).

C-Type Lectin Domain Family 3 Member B (CLEC3B), a member of the C-type lectin superfamily, encodes tetranectin in cells (8). Tetranectin was originally isolated from human plasma in 1986 (9). Tetranectin binds to kringle 4 of plasminogen in a lysine-dependent manner and regulates proteolytic processes via the activation of plasminogen (9). Tetranectin has been reported to regulate mineralization in osteogenesis (10), myogenesis and muscle development (11) in addition to cardiovascular disease $(12,13)$. A previous study has also proposed a neuroprotective role of this gene in Parkinson's disease (14).

In malignancies, the expression and function of CLEC3B remain poorly studied and controversial. A decreased level of tetranectin was identified in blood samples from patients with various cancer types, including ovarian cancer, myeloma, breast cancer, colon carcinoma, B-chronic lymphocytic leukemia, oral and pancreatic cancer (15-19), but not in blood samples from patients with endometrial adenocarcinoma (20). Low levels of serum tetranectin correlate with cancer progression and unfavorable survival rates (21) and predict patients with a poor chemotherapy response (22). In addition to the serum, the expression of CLEC3B has also been detected within the stroma and cancer cells of tumor tissues with varied expression statuses and distribution patterns, but the expression of CLEC3B correlates with inverse prognosis outcomes, suggesting that CLEC3B may exert distinct functions in a cancer-specific manner. Chen et al (23) revealed that CLEC3B expression was significantly downregulated in gastric tumor tissues and that a high intratumoral tetranectin level was correlated with advanced tumor progression and shorter survival time. In breast cancer, CLEC3B exhibits high cellular protein expression in $69 \%$ of tumor tissues, predicting a poorer survival time (24). However, positive tetranectin expression in ovarian cancer tissues predicts a more favorable prognosis (25). So far, there are no reports on the genetic alterations, tissue expression and the functional role of CLEC3B in ccRCC. Therefore, the present study aimed to investigate the expression and potential role of CLEC3B in ccRCC.

\section{Materials and methods}

Computational analysis of the CLEC3B transcriptional levels in ccRCC. RNA-seq data for the paired samples of 72 patients with ccRCC (including 20 female and 52 male patients, age range from 38 to 90 , mean age, 62.5) from a The Cancer Genome Atlas (TCGA) dataset (https://cancergenome.nih.gov/) were obtained on July 20, 2017 and Fragments Per Kilobase of transcript per Million normalized expression values were used to compare CLEC3B mRNA expression between cancer tissues and matched normal tissues. For validation, Robust Multi-chip Average normalized mRNA expression data of Beroukhim's ccRCC cohort (GSE14994) from a Gene Expression Omnibus (GEO) database (https:/www.ncbi.nlm.nih.gov/geo/) were obtained on December 12, 2017 and analyzed using the GEO2R online tool (https://www.ncbi.nlm.nih.gov/geo/geo2r/), containing 55 cancerous and 11 non-paired normal kidney tissues.

Immunohistochemistry (IHC) analysis of the CLEC3B protein levels in $c c R C C$. Tissue microarray IHC analysis was performed with a standard protocol to evaluate the expression levels of CLEC3B protein in ccRCC. A total of 19 patients (12 male and 7 female, age range from 39 to 76 , mean age 56.5 who underwent surgical resection between February 2008 and June 2008 at Beijing Chaoyang Hospital) containing tumorous and adjacent normal tissues in a ccRCC tissue microarray were included as valid cases for statistical analysis. Written informed patient consent was obtained from all patients prior to the study. Briefly, the formalin-fixed (24-48 $\mathrm{h}$ at room temperature), paraffin-embedded $\left(58-60^{\circ} \mathrm{C}\right.$ for $\left.\sim 10 \mathrm{~min}\right)$ tissue sections at a thickness of $4 \mu \mathrm{m}$ were initially treated with deparaffinization and hydration, and then subjected to the heat-induced epitope retrieval using $0.01 \mathrm{~mol} /$ citrate buffer at $\mathrm{pH} 6.0$ for $30 \mathrm{~min}$ in a pressure cooker. Sections were blocked with $5 \%$ goat serum for $30 \mathrm{~min}$ at room temperature and were subsequently incubated overnight at $4^{\circ} \mathrm{C}$ with the primary anti-rabbit Tetranectin monoclonal antibody $(1: 300$; cat. no. ab108999, Abcam, Cambridge, UK), and then incubated with horseradish peroxidase-conjugated goat anti-rabbit IgG secondary antibodies (1:1,000; cat. no. ZB-2301; OriGene Technologies, Inc., Rockville, MD, USA) for $30 \mathrm{~min}$ at $4^{\circ} \mathrm{C}$. Immunolabeling was detected using a diaminobenzidine (DAB) Detection kit (cat. no. ZLI-9017; OriGene Technologies, Inc.). Subsequent to rinsing in water for $10 \mathrm{~min}$, the sections were counterstained with $0.5 \%$ hematoxylin (cat. no. ZLI-9609; OriGene Technologies, Inc.) for $1.5 \mathrm{~min}$ at room temperature. Immunohistochemical signals were captured under a light microscope (Olympus Corporation, Tokyo, Japan) at a magnification of $\mathrm{x} 200$.

Copy number variation analysis. Putative copy-number calls determined using GISTIC 2.0 for the TCGA datasets were analyzed for copy-number variation (CNV) analysis (26). The cBioPortal for Cancer Genomics (http://www.cbioportal.org/) (27) was used to illustrate the CNV status of CLEC3B in ccRCC and other cancer types. Comparison of the copy numbers in 489 ccRCC tissues, 43 papillary renal cell carcinoma tissues, 441 paired normal kidney tissues and 98 paired normal blood specimens from the TCGA dataset was conducted using Oncomine analysis (28). The genomic distribution of CLEC3B and VHL was queried in Ensemble (https://asia.ensembl.org/index.html).

Cell line culture. The human ccRCC cell lines 786-O,769-P, ACHN and Caki-1 were all purchased from the National Infrastructure of Cell Line Resources (Beijing, China). Cells were cultured in Dulbecco's modified Eagle's medium (Hyclone; GE Healthcare Life Sciences, Logan, UT, USA) containing 10\% fetal bovine serum (Gibco; Thermo Fisher Scientific, Inc., Waltham, MA, USA) at $37^{\circ} \mathrm{C}$ in a humidified incubator with $5 \% \mathrm{CO}_{2}$.

Plasmid transfection. The complete CLEC3B coding sequence was cloned into the pCMV6-Entry vector (OriGene Technologies, Inc., Rockville, MD, USA), and transfected into 
786-O and 769-P cells using Lipofectamine 2000 (Invitrogen; Thermo Fisher Scientific, Inc.) according to the manufacturer's protocol. pCMV6-Entry vector alone transfection was used as a negative control.

Western blot analysis. For western blot analysis, the transfected and control 786-O and 769-P cells were harvested $48 \mathrm{~h}$ after transfection and lysed in RIPA buffer (Beyotime Institute of Biotechnology, Haimen, China) for $30 \mathrm{~min}$ at $4^{\circ} \mathrm{C}$, and the protein concentrations were quantified using a BCA kit (Sigma-Aldrich; Merck KGaA, Darmstadt, Germany). Samples were boiled in loading buffer for $10 \mathrm{~min}$ at $95^{\circ} \mathrm{C}$. Proteins (40 $\mu \mathrm{g}$ per lane) were loaded and separated by $10 \%$ SDS PAGE and then transferred onto a polyvinylidene fluoride membrane (EMD Millipore, Billerica, MA, USA). The membrane was blocked in 5\% skim milk diluted with tris-buffered saline with $0.1 \%$ Tween-20 (TBST) for $1 \mathrm{~h}$ at $4^{\circ} \mathrm{C}$. Then, the membrane was incubated with the following first antibodies overnight at $4{ }^{\circ} \mathrm{C}$ : Anti-Tetranectin (cat. no. ab108999; 1:1,000 dilution, Abcam), anti- $\beta$-actin (cat. no. \#8457; 1:3,000 dilution), GAPDH (cat. no. \#5174; 1:2,000 dilution), P38 (cat. no. \#9212; 1:1,000 dilution), phosphorylated (p)-P38 (cat. no. \#4511; 1:1,000 dilution), extracellular signal-regulated kinase (ERK; cat. no. \#9102; 1:1,000 dilution), p-ERK (cat. no. \#4376; 1:1,000 dilution) (all Cell Signaling Technology, Inc., Danvers, MA, USA) and anti-Ki-67 (cat. no. ZM-0166; 1:1,000 dilution; OriGene Technologies, Inc.). Following washing with TBST 3 times, the membrane was subsequently incubated with horseradish peroxidase (HRP)-conjugated goat anti-mouse or goat anti-rabbit IgG secondary antibodies (cat. nos. ZB-2305 and ZB-2301; 1:8,000 dilution; OriGene Technologies, Inc.) for $1 \mathrm{~h}$ at $4^{\circ} \mathrm{C}$. Subsequent to the final wash with TBST 3 times, the signal was detected using chemiluminescent HRP substrate (EMD Millipore) on a Bio-Rad imaging system (Bio-Rad ChemiDoc MP, 1708195; Bio-Rad Laboratories, Inc., Hercules, CA, USA). The experiments were replicated at least three times, and the results were analyzed using Image J 1.46r software (National Institutes of Health, Bethesda, MD, USA).

In vitro cell proliferation analysis. A real-time cell analyzer system (RTCA; xCELLigence; ACEA Biosciences, San Diego, CA, USA) was used to monitor the cell proliferation in real-time as previously described (29). This system is able to measure electrical impedance variations and present the results as the cell index which directly reflects cellular proliferation. A total of $48 \mathrm{~h}$ after cell transfection, 3,000 cells/well of 786-O and 769-P cells were seeded in an E-plate. The E-plate was then placed into in a RTCA device at $37^{\circ} \mathrm{C}$ with $5 \% \mathrm{CO}_{2}$, and the cell index was recorded automatically at 15 -min intervals. The recorded curve is presented as the cell index \pm standard error of the mean.

Co-expression analysis. The TCGA kidney renal clear cell carcinoma (KIRC) cohort $(\mathrm{n}=533)$ and another large ccRCC cohort (GSE2109, n=193) from the GEO database were used to perform co-expression data mining analysis using the R2: Genomics Analysis and Visualization Platform (http://r2.amc.nl). For the selection of co-expressing genes in the TCGA cohort, a screening criterion of $\mathrm{P}<0.00000001$ was used, while for co-expressing genes in the GSE2109 cohort, the screening criteria used was $\mathrm{P}<0.001$. For Gene Ontology (GO) analysis of the enriched biological processes (30), the Database for Annotation, Visualization and Integrated Discovery (DAVID) Bioinformatics Resources 6.8 was used (31).

Statistical analysis. Statistical analyses were performed using GraphPad Prism 7.0 (GraphPad Software, Inc., La Jolla, CA, USA) or SPSS Statistics version 22 (IBM Corp., Armonk, NY, USA). A paired Student's t-test was used to compare CLEC3B mRNA expression in 72 TCGA paired samples, and a Mann-Whitney U test was used for unpaired samples in GSE14994. To compare CLEC3B protein levels in the 19 paired ccRCC tissues, a Binomial test was used. To determine the association between CLEC3B and clinicopathological features, a Mann-Whitney U test was used and the CLEC3B expression in TCGA KIRC samples were stratified based on the American Joint Committee on Cancer Tumor Node Metastasis (TNM) staging system (32) or Institute of Statistics of the University of Paris/World Health Organization grading system $(32,33)$. For TNM, T: Size or direct extent of the primary tumor; N: Degree of spread to reginal lymph nodes; M: Presence of distant metastasis. For staging, stage I: T1 N0 M0; stage II: T2 N0 M0; stage III: T3 or N1 with M0; stage IV: T4 or M1. For grading, grade 1: tumors have nucleoli that are inconspicuous and basophilic at a x400 magnification; grade 2: tumors have nucleoli that are clearly visible at a x400 magnification and are eosinophilic; grade 3: Tumors have clearly visible nucleoli at a x100 magnification; grade 4: Tumors have extreme pleomorphism or rhabdoid and/or sarcomatoid morphology. For Kaplan-Meier analyses, the cut-off values (727 and 797.7, respectively) for overall survival (OS) and disease-free survival (DFS) rates were determined by the receiver operating characteristic curve method and a log-rank test was used to compare different survival curves. The Cox regression model was used for univariate and multivariate survival analyses. For all correlation analyses in the present study, a Pearson's test was used. The data were presented as the mean \pm standard deviation. $\mathrm{P}<0.05$ was considered to indicate a statistically significant difference.

\section{Results}

CLEC3B is downregulated in ccRCC. To examine the expression status of CLEC3B in ccRCC, RNA-seq data from 72 patients with cancer and matched adjacent normal tissues in the TCGA KIRC dataset was analyzed. The results revealed that in comparison with the matched normal tissue, CLEC3B mRNA was significantly downregulated in the cancerous tissue from $76.4 \%$ (55 of 72) of the patients with ccRCC $(\mathrm{P}<0.0001$; paired Student's t-test; Fig. 1A and B). The downregulation of CLEC3B at the transcriptional level was further verified in a GEO ccRCC dataset (GSE14994) from Beroukhim (34) ( $\mathrm{P}=0.0392$; Mann-Whitney U test; Fig. 1C). To further validate this result, IHC staining was performed to assess CLEC3B expression at the protein level in a cohort of 19 patients with ccRCC with cancer and matched adjacent noncancerous tissues. In line with the aforementioned mRNA results, a significant downregulation of CLEC3B protein levels in matched ccRCC tissues (Fig. 1D), was observed in $78.9 \%$ (15 of 19) of patients compared with the normal tissues 

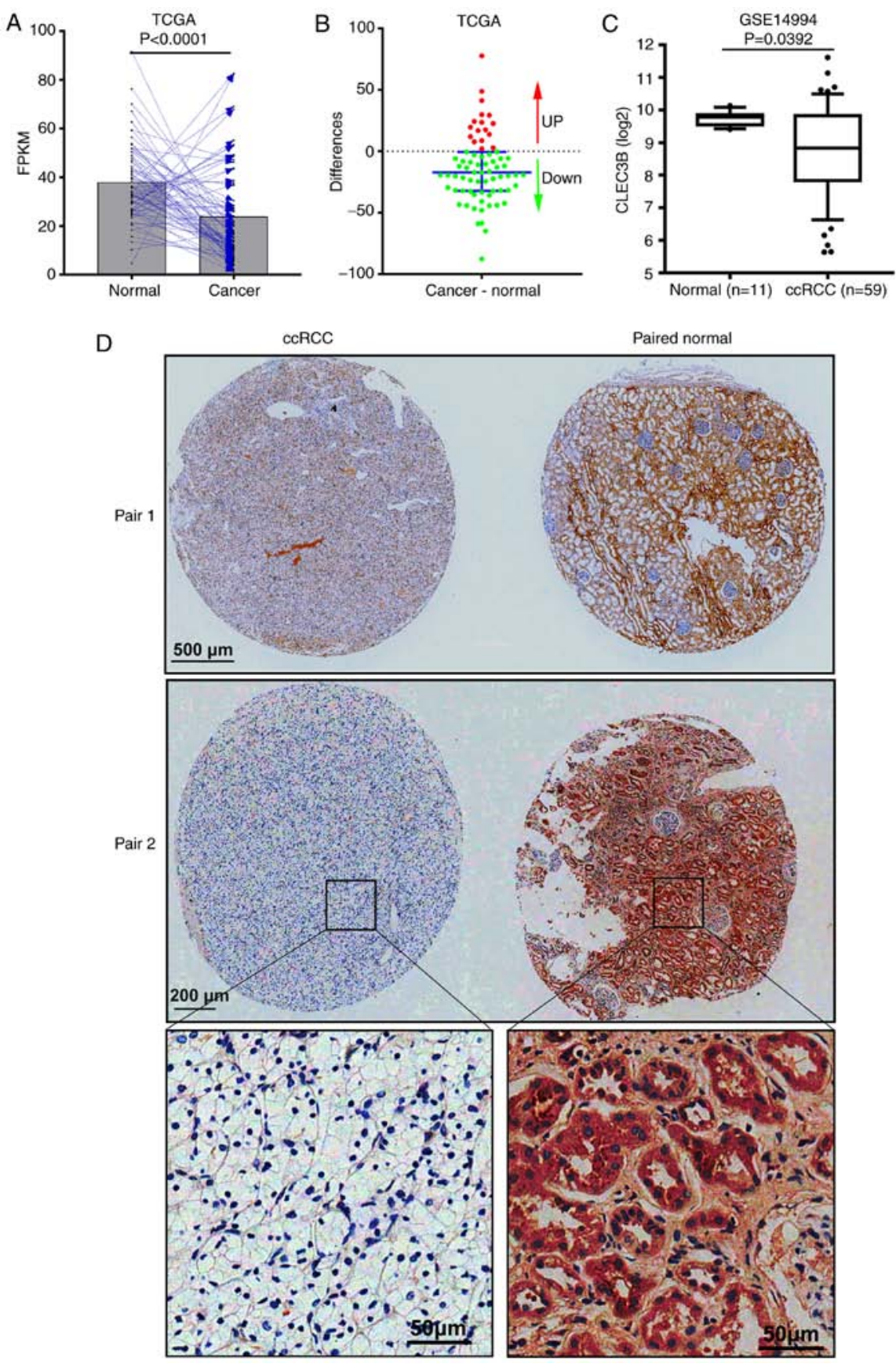

Figure 1. CLEC3B is downregulated in ccRCC. (A) CLEC3B mRNA is significantly downregulated in ccRCC compared with matched adjacent normal from the TCGA kidney renal clear cell carcinoma dataset $(\mathrm{P}<0.0001)$. (B) Differences in CLEC3B expression between cancer and normal tissues in the aforementioned 72 patients. The dots represent the difference value of cancer CLEC3B subtracted by normal CLEC3B for every patient. The red dots represent a positive difference value, indicating that CLEC3B is upregulated in cancer; while the green dots represent a negative difference value, indicating that CLEC3B is downregulated in cancer. The bar represents the median with the interquartile range. (C) Validation of CLEC3B mRNA downregulation in a Gene Expression Omnibus dataset (GSE14994). (D) Representative images for the paired samples from two patients with ccRCC, demonstrating that CLEC3B was also downregulated in ccRCC tissue compared with normal tissue at the protein level. TCGA, The Cancer Genome Atlas; ccRCC, clear cell renal cell carcinoma; FPKM, Fragments Per Kilobase of transcript per Million; CLEC3B, C-Type Lectin Domain Family 3 Member B.

( $\mathrm{P}=0.019$; Binomial test, two-tailed). These data suggest that CLEC3B is downregulated in ccRCC at the mRNA and protein levels.

Copy number loss of CLEC3B is prevalent and specific in $c c R C C$. DNA CNVs are common in cancer and are responsible for the dysregulation of gene expression (35). To decipher the underlying mechanism resulting in CLEC3B downregulation in ccRCC, copy number alteration analysis was performed using the TCGA KIRC dataset. The results demonstrated that the copy number loss of CLEC3B was detected in up to $88.1 \%$ of patients with ccRCC, including $10.6 \%$ homozygous deletions (deep deletion) and $77.5 \%$ hemizygous deletions. Only a small proportion of patients (11.9\%) were detected to have no change (10.8\%) or a gain of copy number (1.1\%) (Fig. 2A).

Previous studies revealed that $\sim 90 \%$ of ccRCC were associated with the bi-allelic somatic mutation in the VHL tumor suppressor gene $(34,36)$. Therefore, considering the genetic 

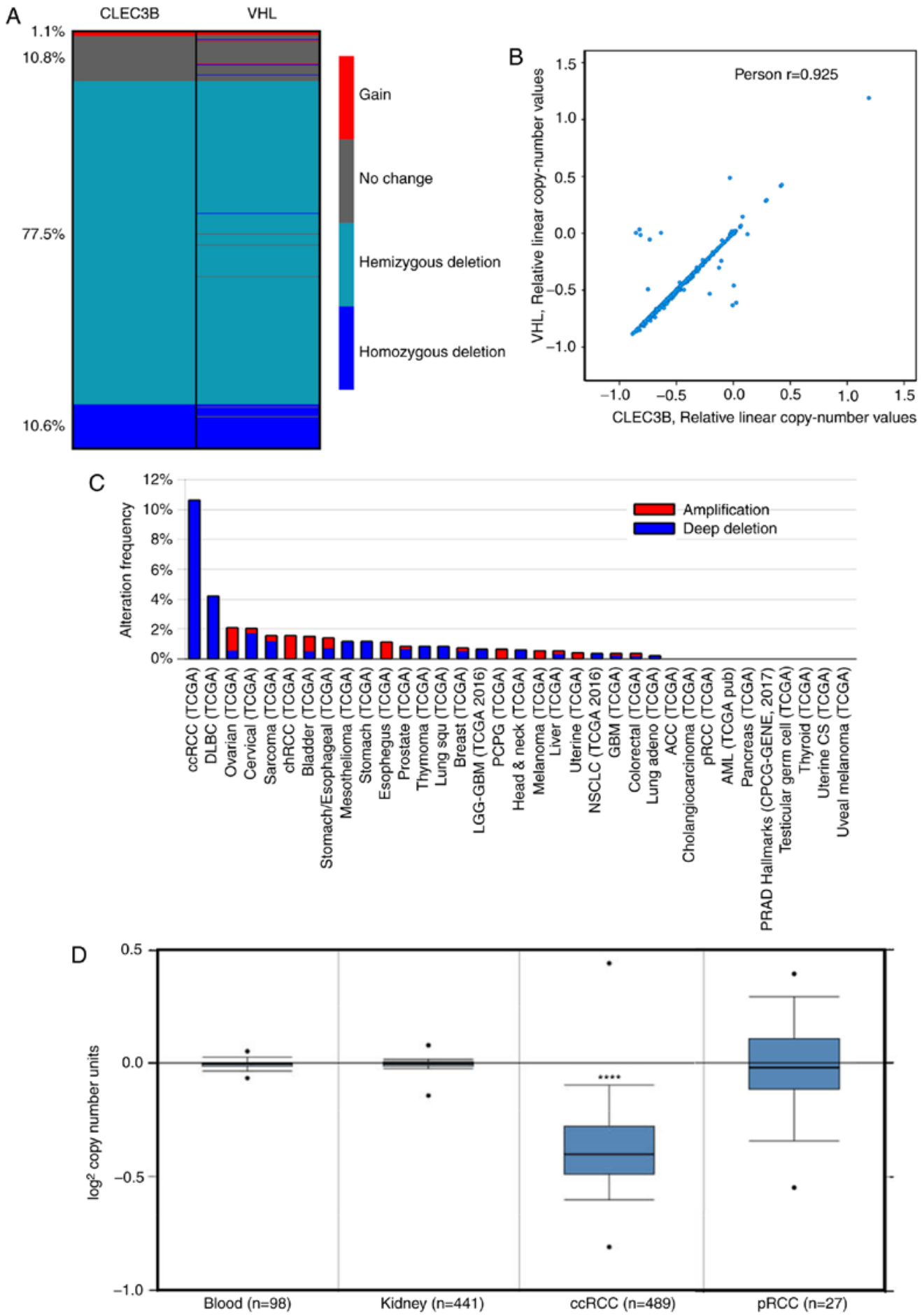

Figure 2. CLEC3B copy number variation analysis using TCGA datasets. (A) Deep deletion of the copy number for CLEC3B and VHL in patients with ccRCC from the a TCGA kidney renal clear cell carcinoma dataset. (B) A significant correlation between the residual copy numbers of CLEC3B and VHL was identified using Pearson's correlation analysis. (C) The frequency of deep deletion in the CLEC3B copy number was substantially higher in ccRCC compared with other cancer types. (D) CLEC3B copy number in ccRCC but not pRCC was signifcantly lower compared with normal tissues. CLEC3B, C-Type Lectin Domain Family 3 Member B; VHL, von Hippel-Lindau Tumor Suppressor; TCGA, The Cancer Genome Atlas; ccRCC, clear cell renal cell carcinoma; pRCC, papillary renal cell carcinoma.

alterations between CLEC3B and VHL, it was revealed that the CNVs of these two genes shared a similar deletion pattern in ccRCC (Fig. 2A), and that the residual copy numbers of the two genes were significantly correlated (Pearson's; $r=0.925$, $\mathrm{P}<0.0001$; Fig. 2B). Further inspection revealed that these two genes are closely distributed in the genome, CLEC3B in 3p21.31 and VHL in 3p25.3, by Ensembl. Together, these data indicate that the copy number loss events of CLEC3B and VHL are potentially coupled during ccRCC tumorigenesis.

It was additionally observed that the copy number loss of the CLEC3B gene appeared to be specific to ccRCC, as the deep deletion frequency was substantially higher in ccRCC compared with all other cancer types in the TCGA project (Fig. 2C). To delineate the potential role of copy number 
Table I. Association between CLEC3B and the clinicopathological features of clear cell renal cell carcinoma.

\begin{tabular}{|c|c|c|c|c|}
\hline \multirow[b]{2}{*}{ Clinicopathological features } & \multirow[b]{2}{*}{ All cases } & \multicolumn{2}{|c|}{ CLEC3B expression } & \multirow[b]{2}{*}{ P-value } \\
\hline & & Mean & $95 \%$ confidence interval & \\
\hline Sex & & & & 0.0624 \\
\hline Female & 188 & 1,120 & $994.5-1,246$ & \\
\hline Male & 345 & 1,080 & $943.2-1,218$ & \\
\hline Age & & & & 0.9971 \\
\hline$\leq 60$ & 265 & 1,056 & $942.3-1,169$ & \\
\hline$>60$ & 268 & 1,133 & $970.3-1,296$ & \\
\hline $\mathrm{T}$ & & & & $<0.0001$ \\
\hline $\mathrm{T} 1-\mathrm{T} 2$ & 342 & 1,243 & $1,102-1,383$ & \\
\hline $\mathrm{T} 3-\mathrm{T} 4$ & 191 & 829.5 & $723.5-935.4$ & \\
\hline $\mathrm{N}$ & & & & 0.0107 \\
\hline N0 & 239 & 1,014 & $843.3-1,184$ & \\
\hline N1 & 16 & 492.6 & $235.5-749.8$ & \\
\hline M & & & & 0.0001 \\
\hline M0 & 442 & 1,154 & $1,039-1,268$ & \\
\hline M1 & 81 & 722 & $571.8-872.2$ & \\
\hline Stage & & & & $<0.0001$ \\
\hline Stage I-II & 324 & 1,266 & $1,121-1,412$ & \\
\hline Stage III-IV & 206 & 831.9 & 726.1-937.7 & \\
\hline Grade & & & & $<0.0001$ \\
\hline G1-G2 & 242 & 1,302 & $1,138-1,466$ & \\
\hline G3-G4 & 283 & 886.5 & 775.4-997.6 & \\
\hline
\end{tabular}

A Mann Whitney test was used for statistical analysis. T, size or direct extent of the primary tumor; N, degree of spread to reginal lymph nodes; M, presence of distant metastasis; CLEC3B, C-Type Lectin Domain Family 3 Member B.

loss in ccRCC development, the CNVs of the CLEC3B gene in 489 ccRCC samples, 441 paired normal kidney tissue samples and 98 paired normal blood specimen samples from TCGA dataset were assessed. The results revealed that the CLEC3B gene copy number in ccRCC was significantly lower compared with that in normal tissues $\left(\mathrm{P}=1.07 \times 10^{-163}\right.$; Student's t-test; Fig. 2D); however, no significant change was detected in another RCC subtype, pRCC $(\mathrm{P}=0.384$; Student's t-test; Fig. 2D). These results indicate that the copy number loss is a ccRCC-specific oncogenic driving event during tumorigenesis.

CLEC3B downregulation is associated with ccRCC progression and prognosis. The association of CLEC3B downregulation with the clinicopathologic features of the TCGA KIRC cohort were then evaluated. The results revealed that the downregulated expression of CLEC3B was significantly associated with a higher size or direct extent of the primary tumor status of the tumor $(\mathrm{P}<0.0001)$, higher lymph node metastasis $(\mathrm{P}=0.0107)$, higher distant metastasis $(\mathrm{P}=0.0001)$, more advanced clinical stage $(\mathrm{P}<0.0001)$ and lower differentiation $(\mathrm{P}<0.0001)$ but not with sex $(\mathrm{P}=0.0624)$ or age $(\mathrm{P}=0.9971)$ (Table I, Fig. 3A).

Kaplan-Meier survival analysis revealed that patients with ccRCC with lower CLEC3B demonstrated a significantly poorer OS and DFS rates compared with those with a high expression of CLEC3B ( $\mathrm{P}<0.05$; Fig. 3B). Further multivariate Cox regression analysis demonstrated that CLEC3B downregulation was an independent prognostic factor for poor OS rate [hazard ratio (HR) $0.722 ; 95 \%$ confidence interval $(\mathrm{CI}), 0.528$ to $0.987 ; \mathrm{P}=0.041$; Table II) and DFS rate (HR, $0.408 ; 95 \% \mathrm{CI}$, 0.587 to $0.845 ; \mathrm{P}=0.004$, Table III). In conclusion, these results suggested that the downregulation of CLEC3B was frequently detected in ccRCC and that its downregulation was associated with a higher aggressiveness and poorer prognosis in patients with ccRCC.

Induced CLEC3B expression decreases the proliferation of ccRCC cell lines in vitro. To investigate the impact of CLEC3B on ccRCC in vitro, the baseline levels of endogenous CLEC3B in a panel of 4 ccRCC cell lines (786-O,769-P, ACHN and Caki-1) were measured using western blot analysis (Fig. 4A). It was revealed that the 786-O,769-P and Caki-1 cell lines produced substantially lower levels of endogenous CLEC3B expression compared with the ACHN cell line, and 786-O and 769-P were selected for a transient overexpression study. A total of $48 \mathrm{~h}$ after transfection, the cells were collected and the successful overexpression of CLEC3B in these two cell lines was confirmed by western blot analysis 
Table II. Univariate and multivariate Cox regression analyses of overall survival rate in patients with clear cell renal cell carcinoma from The Cancer Genome Atlas dataset.

Univariate Cox regression

\begin{tabular}{|c|c|c|c|c|}
\hline Variables & Classification & \multicolumn{2}{|c|}{ Overall survival [hazard ratio $(95 \% \mathrm{CI})]$} & P-value \\
\hline Sex & Female vs. male & $\mapsto$ & $1.036(0.754,1.425)$ & 0.826 \\
\hline Age & $\leq 60$ vs. $>60$ & & $1.406(1.039,1.902)$ & 0.027 \\
\hline $\mathrm{T}$ & T1-T2 vs. T3-T4 & & $3.079(2.269,4.179)$ & $<0.001$ \\
\hline M & M0 vs. M1 & 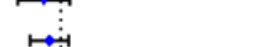 & $0.719(0.451,1.146)$ & 0.166 \\
\hline Stage & Stage I-II vs. Stage III-IV & ar & $0.822(0.603,1.122)$ & 0.218 \\
\hline Grade & G1-G2 vs. G3-G4 & 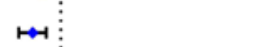 & $0.718(0.532,0.969)$ & 0.030 \\
\hline CLEC3B & Low vs. High & $\frac{1}{2}$ & $0.604(0.446,0.818)$ & 0.001 \\
\hline
\end{tabular}

Multivariate Cox regression

Variables

Classification

Overall survival [hazard ratio $(95 \% \mathrm{CI})]$

P-value

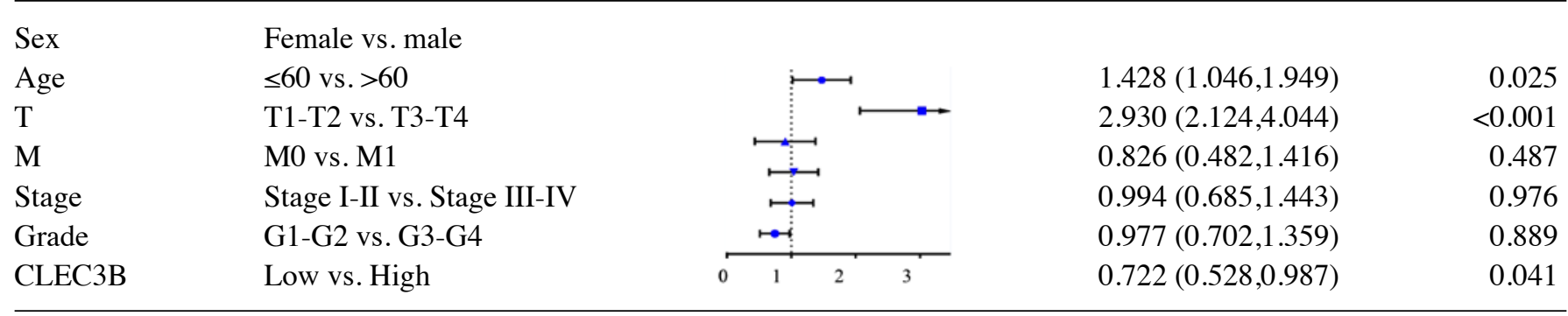

A Log-rank test was used for statistical analysis. CI, confidence interval; T, size or direct extent of the primary tumor; M, presence of distant metastasis; CLEC3B, C-Type Lectin Domain Family 3 Member B.
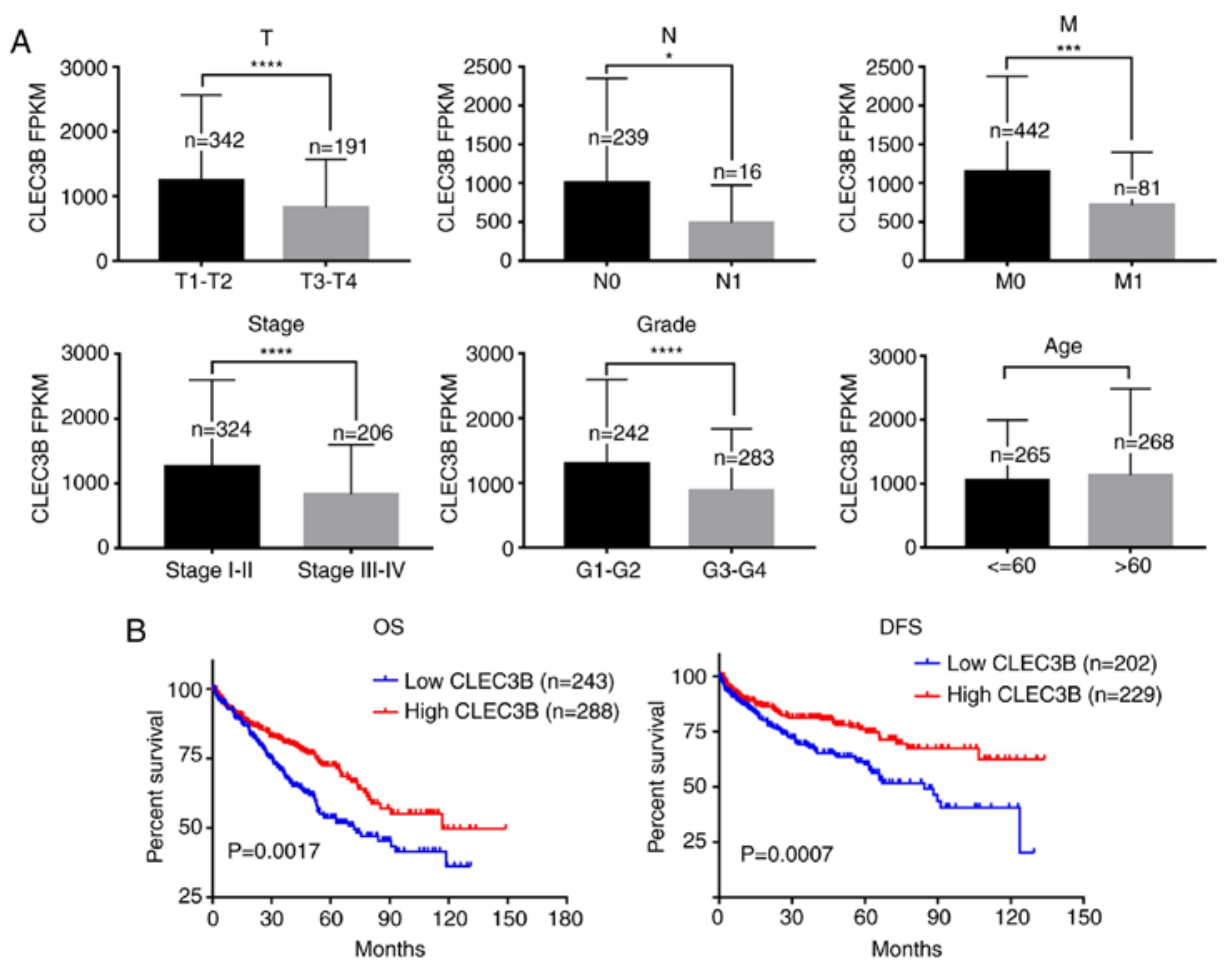

Figure 3. CLEC3B downregulation is associated with ccRCC progression and prognosis. (A) CLEC3B is significantly downregulated in ccRCC specimens with higher TNM stage or grade compared with normal tissues, but is not significantly associated with age. (B) Kaplan-Meier survival analysis revealed the association between CLEC3B and OS or DFS rates. ${ }^{*} \mathrm{P}<0.05,{ }^{* * *} \mathrm{P}<0.001$ and ${ }^{* * * *} \mathrm{P}<0.0001$ with comparisons show by lines. CLEC $3 \mathrm{~B}$, C-Type Lectin Domain Family 3 Member B; T, size or direct extent of the primary tumor; N, degree of spread to reginal lymph nodes; M, presence of distant metastasis; OS, overall survival; DFS, disease-free survival; ccRCC, clear cell renal cell carcinoma. 
Table III. Univariate and multivariate Cox regression analyses of DFS rate in patients with clear cell renal cell carcinoma from The Cancer Genome Atlas dataset.

Univariate Cox regression

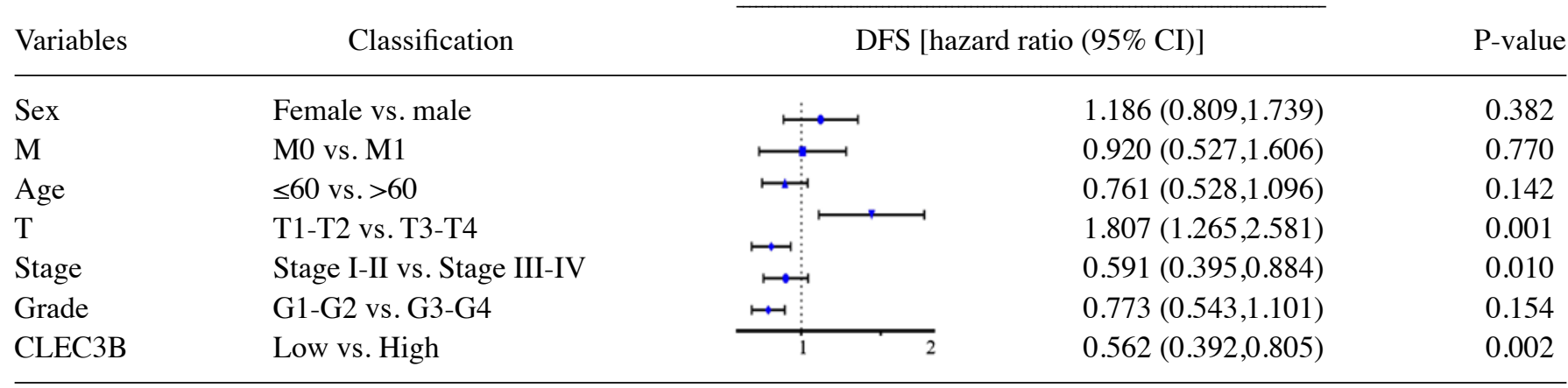

Multivariate Cox regression

DFS [hazard ratio $(95 \% \mathrm{CI})]$

P-value

\begin{tabular}{lllll}
\hline Sex & Female vs. male & & \\
$\mathrm{M}$ & M0 vs. M1 & $1.411(0.815,2.433)$ & 0.218 \\
$\mathrm{Age}$ & $\leq 60$ vs. $>60$ & $1.820(1.265,2.618)$ & 0.001 \\
$\mathrm{~T}$ & $\mathrm{~T} 1-\mathrm{T} 2$ vs. T3-T4 & $0.405(0.219,0.794)$ & 0.004 \\
Stage & Stage I-II vs. Stage III-IV & $0.881(0.608,1.275)$ & 0.500 \\
Grade & G1-G2 vs. G3-G4 & $0.408(0.587,0.845)$ & 0.004 \\
CLEC3B & Low vs. High & &
\end{tabular}

A Log-rank test was used for statistical analysis. CI, confidence interval; DFS, disease-free survival; T, size or direct extent of the primary tumor; M, presence of distant metastasis; CLEC3B, C-Type Lectin Domain Family 3 Member B.

(Fig. 4B). The transfected cells were then subjected to a cell growth assay using a RTCA. The results demonstrated that the forced expression of CLEC3B notably reduced proliferation in the two cell lines compared with the negative control (Fig. 4C). Repression of proliferation was also indicated by the significantly decreased level of the proliferative cellular marker Ki-67 in 786-O cells transfected with CLEC3B compared with the negative control $(\mathrm{P}<0.01$; Fig. 4D and $\mathrm{E})$. The mitogen-activated protein kinase (MAPK) signaling pathway serves a key role in the regulation of cancer cell proliferation (37). To decipher the potential underlying mechanism, the effect of CLEC3B on the MAPK pathway in 786-O cells was investigated and it was revealed that CLEC3B overexpression resulted in a significant decrease of p38, p-p38, ERK and p-ERK compared with the negative control $(\mathrm{P}<0.05$; Fig. $4 \mathrm{D}$ and $\mathrm{E})$, suggesting that the MAPK pathway may contribute to the CLEC3B-mediated ccRCC proliferation inhibition.

CLEC3B identifies ccRCCs with lower proliferation. The gene co-expression network is crucial to elucidate gene function, identify groups of genes that respond in a coordinated manner to environmental or disease conditions, and highlight regulatory associations (38). To address the function of CLEC3B in patients with ccRCC, co-expression analysis using the TCGA KIRC dataset was performed. As presented in Fig. 5A, CLEC3B exhibited an inverse association with known proliferation inducers [MET proto-oncogene, receptor tyrosine kinase (39), epithelial cell transforming 2 (40) and enhancer of zeste 2 polycomb repressive complex 2 subunit (41)], proliferative markers (marker of proliferation Ki-67 and proliferating cell nuclear antigen) and Minichromosome Maintenance genes (42), and revealed a positive association with a spectrum of proliferation inhibitors, including frizzled related protein (43), cadherin 13 (44), sprouty RTK signaling antagonist 1 (45), SRY-box 7 (46), cyclin dependent kinase inhibitor 2B (47), adenosine deaminase, RNA specific B1 (48), DLC1 RhO GTPase activating protein (49), SH3 domain binding protein 4 (50) and DAB2 interacting protein (51), indicating a negative function of CLEC3B in controlling proliferation in the TCGA cohort. To validate this result, verification analysis was performed using another ccRCC cohort (GSE2109, n=193) from the GEO database, and revealed similar association trends for CLECB with all the above proliferative factors (Fig. 5B). This consistency indicates towards the anti-proliferation function of CLEC3B in ccRCC tissues, in accordance with the in vitro functional results. Furthermore, a significant negative correlation between CLEC3B and p38 in the TCGA dataset was identified (Pearson's, $r=-0.284, \mathrm{P}=2.4 \times 10^{-11}$; data not shown). To provide a deeper understanding of the potential mechanism that CLEC3B employs to modulate proliferation, GO analysis with CLEC3B co-expressing genes in the TCGA 
A
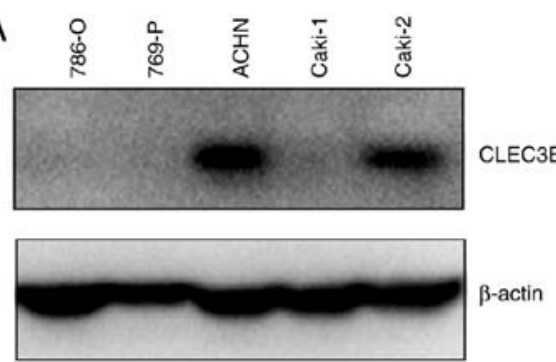

C
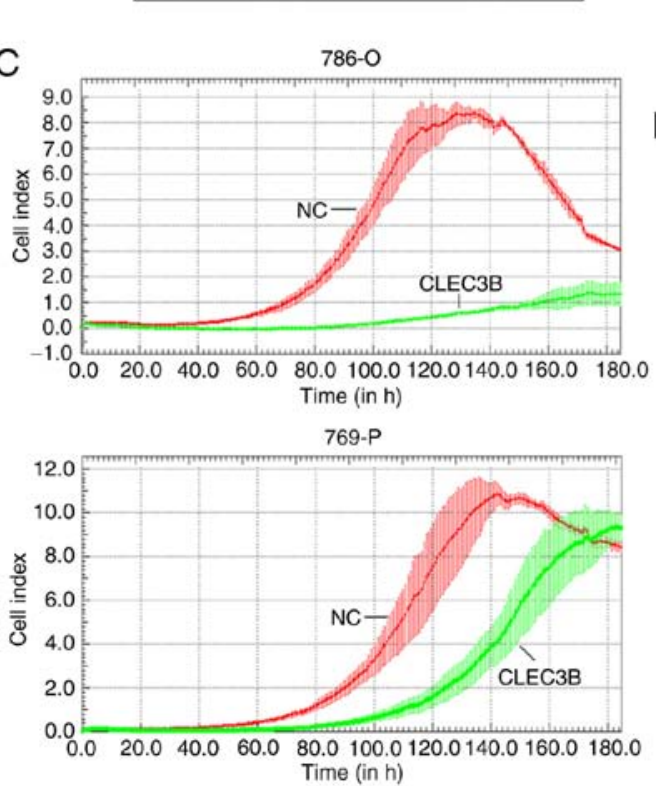

B
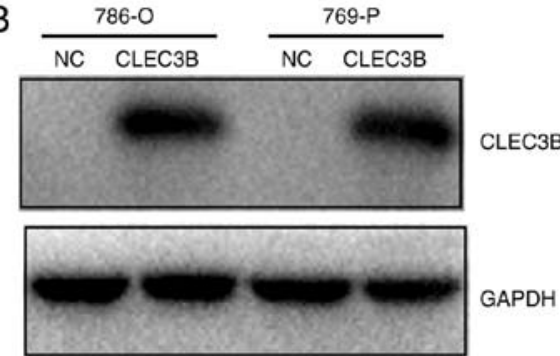
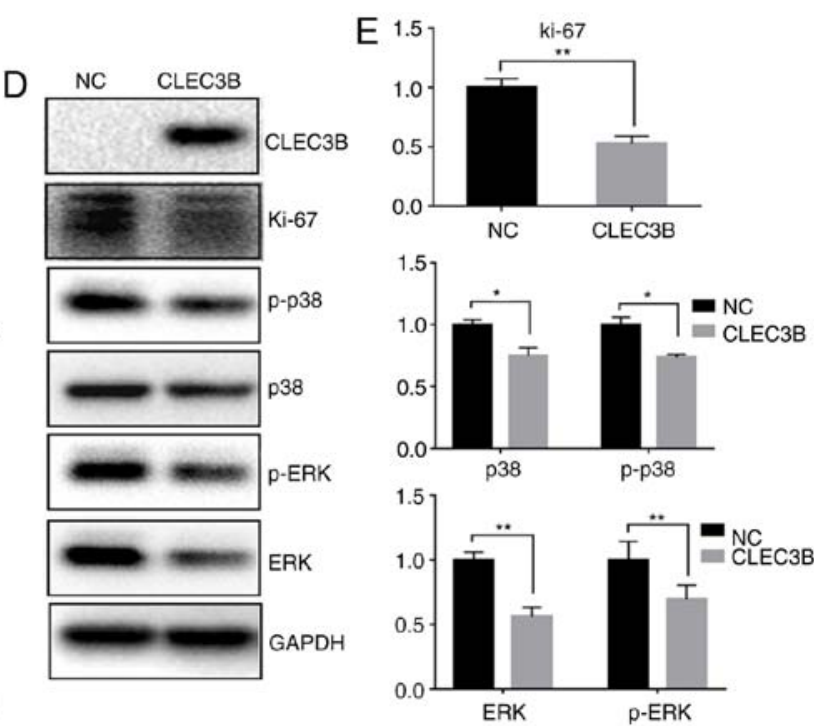

Figure 4. CLEC3B expression inhibits ccRCC cell proliferation in vitro. (A) Endogenous CLEC3B expression status in five ccRCC cell lines. (B) Western blot analysis revealed the ectopic expression of exogenous CLEC3B in CLEC3B-transfected 786-O and 769-P cells. (C) Effect of CLEC3B overexpression on the growth of 786-O and 769-P cells as measured by a real-time cell analyzer system. (D) Expression of Ki-67, p38, p-p38, ERK and p-ERK, was detected by western blot analysis in CLEC3B-transfected 786-O cells. (E) Semi-quantitative analysis of western blot analysis. ${ }^{*} \mathrm{P}<0.05$ and ${ }^{* *} \mathrm{P}<0.01$ with comparisons shown by lines. CLEC3B, C-Type Lectin Domain Family 3 Member B; NC, negative control; p-, phosphorylated; ERK, extracellular signal-regulated kinases; ccRCC, clear cell renal cell carcinoma.

and GSE2109 ccRCC cohorts was performed. A total of 3,260 associated genes $(1,912$ positives and 1,348 negatives) were selected from the TCGA dataset according to a screening criterion of $\mathrm{P}<0.00000001$, and 1,947 associated genes (1,282 positives and 665 negatives) were selected from GSE2109 using a screening criterion of $\mathrm{P}<0.001$. The results revealed that in the two large ccRCC cohorts, the co-expressing genes were most highly enriched in the cell cycle (data not shown), a regulatory event that is directly associated with the control of cell proliferation. The other two most common highly enriched functional items were development and kinase.

The 500 most positive and 500 most negative co-expressers for CLEC3B were extracted from the two cohorts according to the R-value. Significant overlaps were identified for positive co-expressers $(247 ; 49.4 \%$; Fig. 5C) and negative co-expressers (158; 31.6\%; Fig. 5D) in these two groups, indicating the high reliability and sensitivity of the co-expression analysis. To gain a more reliable interpretation, $\mathrm{GO}$ analyses were conducted on the overlapped positive and negative co-expressers in DAVID. The results revealed that the overlapped positive co-expressers were enriched in development processes (Fig. 5E), while the negative co-expressers notably focused on the cell cycle process (Fig. 5F).

\section{Discussion}

Although the dysregulation of CLEC3B in various cancer types has been observed for decades, its expression and function remain obscure. Decreased levels of plasma CLEC3B are consistent in the majority cancer types, but the expression and prognostic significance of CLEC3B in cancer tissues remain controversial $(15,16,24,52,53)$. To evaluate the expression of CLEC3B in ccRCC, which had not yet been reported, the present study conducted a computational profiling of the TCGA KIRC dataset and revealed a significant downregulation of the CLEC3B transcript in tumor tissues. Decreased CLEC3B protein expression in ccRCC was further validated by IHC staining with a specific antibody against tetranectin, suggesting that CLEC3B is downregulated in ccRCC at the mRNA and protein levels.

Genetic alterations, including CNVs, serve an essential role in the dysregulation of cancer genes (54). In the present study, by analyzing CNV data from the TCGA database, it was revealed that CLEC3B loss was notably prevalent in up to $88.1 \%$ of ccRCCs, including a homozygous deletion in $10.6 \%$ of cases. The present study revealed that the copy number loss of CLEC3B is high in ccRCC, but is not notable in other cancer types, suggesting that CLEC3B loss is a ccRCC-specific event. 
A

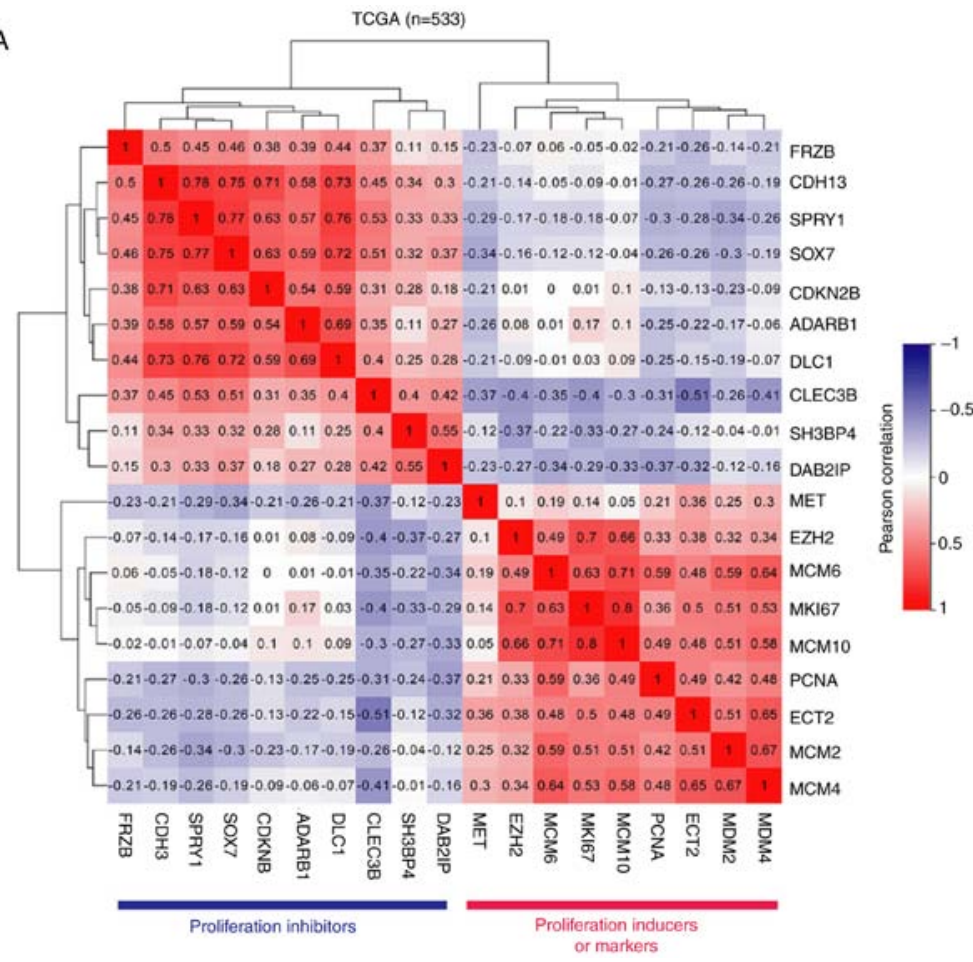

B

GSE2109 $(n=193)$

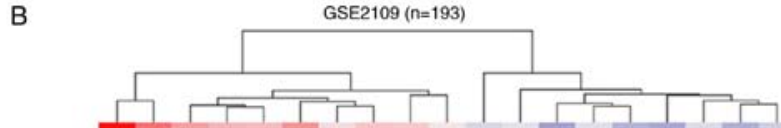

$0.54 \quad 0.36 \quad 0.27 \quad 0.26 \quad 0.410 .13 \quad 0.22 \quad 0.2 \quad 0.09-0.15-0.11-0.36-0.12-0.29-0.33 \cdot 0.14-0.3 \cdot 0.19$ SH3BP4

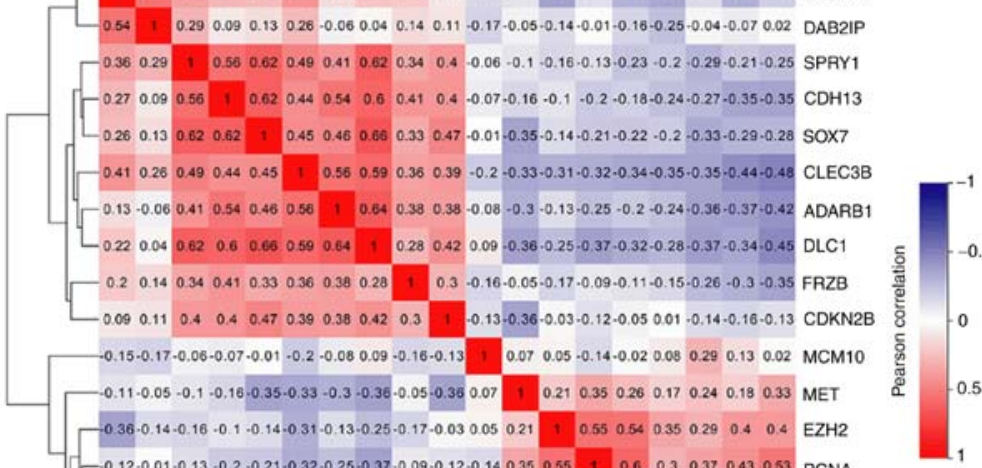

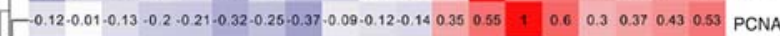
L $-2.29 \cdot 0.16 \cdot 0.23 \cdot 0.18 \cdot 0.22-0.34 \cdot 0.2 \cdot 0.32-0.11 \cdot 0.05 \cdot 0.020 .260 .540 .6$ 1 0.440 .430 .510 .56 MCM6

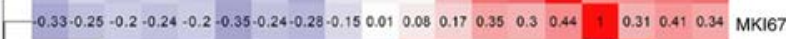
- $0.14 \cdot 0.04 \cdot 0.29 \cdot 0.27-0.33-0.35 \cdot 0.36-0.37-0.28 \cdot 0.140 .290 .240 .290 .370 .430 .31$ I 0.440 .47 MCM2

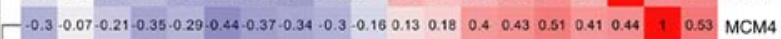

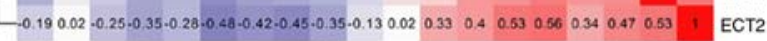

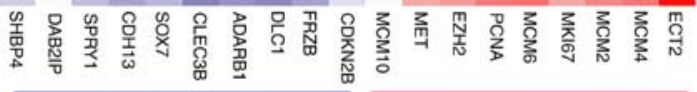
Proliferation inhibitors Proliferation inducers or markers

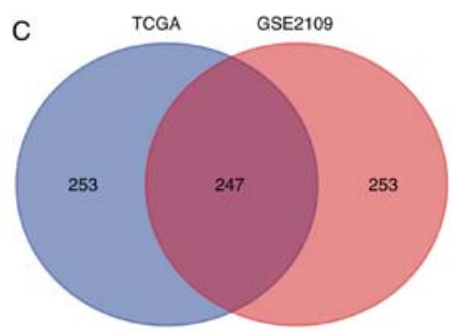

Positive correlation

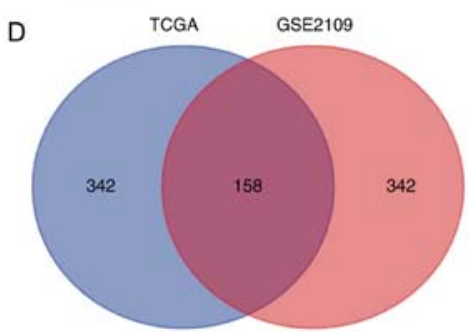

Negative correlation

Figure 5. CLEC3B identifies clear cell renal cell carcinoma with low proliferation properties. CLEC3B is inversely associated with proliferation inducers and markers and is positively associated with proliferation repressors in two cohorts from (A) TCGA and (B) GSE2109. The Venn diagram reveals the overlap of the (C) positive co-expressing genes and (D) negative co-expressing genes in the two cohorts. TCGA, The Cancer Genome Atlas; BP, biological processes; CLEC3B, C-Type Lectin Domain Family 3 Member B. 
E

Overlapped positive coexpression genes, BP, top 15
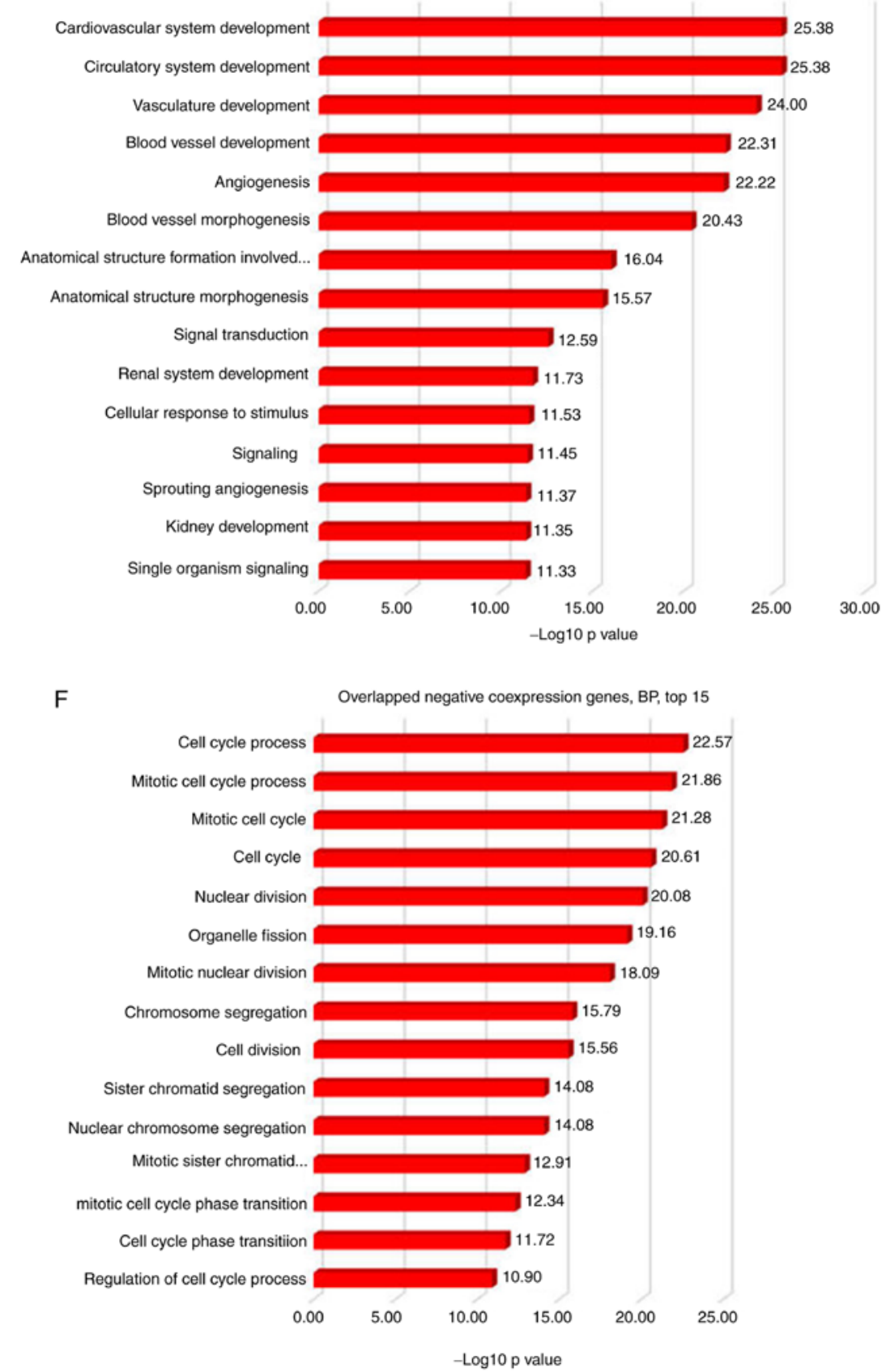

Figure 5. Continued. CLEC3B identifies clear cell renal cell carcinoma with low proliferation properties. Gene Ontology analyses using the Database for Annotation, Visualization and Integrated Discovery were performed on the overlapped (E) positive co-expressing genes and (F) negative co-expressing genes, and only the top $15 \mathrm{BP}$ were presented.

The chromosomal loss in the VHL gene locus is the characteristic genetic alteration of ccRCC and is believed to increase the risk of developing ccRCC $(5,7)$. In the present study it was revealed that the CLEC3B gene is lost in a similar way to VHL, suggesting that they are two tightly coupled events in ccRCC. Given that VHL loss is an early oncogenic driving event in ccRCC tumorigenesis (5), it was hypothesized that CLEC3B genetic loss is also a characteristic signature in the ccRCC carcinogenic process, which has not yet been revealed.

The present study also demonstrated that CLEC3B downregulation in ccRCC correlates with more aggressive features and predicts unfavorable prognostic outcomes for OS and DFS rates in the TCGA cohort. The in vitro cell line experiments indicate that CLEC3B functions to inhibit the proliferation of ccRCC cell lines, and that the mechanism may involve the MAPK pathway.

The co-expression network is a useful method to identify genes that are coordinated under a similar functional framework or disease conditions $(38,55)$. The present study verified that CLEC3B was positively associated with proliferation inhibitors and inversely associated with proliferation inducers or markers from two large independent ccRCC cohorts, strongly indicating the anti-proliferation function of CLEC3B in ccRCC, which was concurrent with the in vitro cell line results. The co-expressing genes from the two cohorts were the most functionally enriched in the cell cycle according to 
GO analysis, an underlying mechanism that directly affects cell proliferation, and additionally in development. Functional clustering analysis using DAVID with the most highly associated and common co-expressers from the two cohorts revealed that the regulation of development (particularly in the cardiovascular and renal system) may occur via CLEC3B and its positive co-expressers, while cooperation between CLEC3B and its negative co-expressers may be responsible for cell cycle regulation. The role of CLEC3B in muscle development in addition to cardiovascular disease has already been described (11-13), but its role in cell cycle regulation remains unexplored and requires future study.

\section{Acknowledgments}

Not applicable.

\section{Funding}

The present study was supported by the National Natural Science Foundation of China (grant no. 81502384 to Dr Jian Liu, grant no. 81572825 to Professor Guangyu An and grant no. 81672338 to Professor Tao Wen) and the Beijing Natural Science Foundation (grant no. 7172083 to Professor Guangyu An).

\section{Availability of data and materials}

The datasets used and/or analyzed during the current study are available from the corresponding author on reasonable request.

\section{Authors' contributions}

GA and TW designed the study. JL, ZL and QL generated the majority of the data. LL performed the western blot analysis. XF constructed the plasmids and performed the transfection. $\mathrm{JL}$ was a major contributor in writing the manuscript. All authors read and approved the final manuscript.

\section{Ethics approval and consent to participate}

The present study was approved by the Ethics Committee of Beijing Chao-Yang Hospital, Capital Medical University (approval no. 2017-8-23-17).

\section{Patient consent for publication}

Written informed consent was obtained from all patients prior to the study.

\section{Competing interests}

The authors declare that they have no competing interests.

\section{References}

1. Siegel RL, Miller KD and Jemal A: Cancer statistics, 2017. CA Cancer J Clin 67: 7-30, 2017.

2. Rini BI, Campbell SC and Escudier B: Renal cell carcinoma. Lancet 373: 1119-1132, 2009.
3. Wolff I, May M, Hoschke B, Zigeuner R, Cindolo L, Hutterer G, Schips L, De Cobelli O, Rocco B, De Nunzio C, et al: Do we need new high-risk criteria for surgically treated renal cancer patients to improve the outcome of future clinical trials in the adjuvant setting? Results of a comprehensive analysis based on the multicenter CORONA database. Eur J Surg Oncol 42: 744-750, 2016.

4. Chen F, Zhang Y, Senbabaoğlu Y, Ciriello G, Yang L, Reznik E Shuch B, Micevic G, De Velasco G, Shinbrot E, et al: Multilevel genomics-based taxonomy of renal cell carcinoma. Cell Rep 14: 2476-2489, 2016.

5. Kaelin WG Jr: The von Hippel-Lindau tumor suppressor gene and kidney cancer. Clin Cancer Res 10: 6290S-5S, 2004.

6. Hsieh JJ, Purdue MP, Signoretti S, Swanton C, Albiges L, Schmidinger M, Heng DY, Larkin J and Ficarra V: Renal cell carcinoma. Nat Rev Dis Primers 3: 17009, 2017.

7. Iliopoulos O, Kibel A, Gray S and Kaelin WG Jr: Tumour suppression by the human von Hippel-Lindau gene product. Nat Med 1: 822-826, 1995

8. Tanisawa K, Arai Y, Hirose N, Shimokata H, Yamada Y, Kawai H, Kojima M, Obuchi S, Hirano H, Yoshida H, et al: Exome-wide association study identifies CLEC3B missense variant p.S106G as being associated with extreme longevity in east asian populations. J Gerontol A Biol Sci Med Sci 72: 309-318, 2017.

9. Clemmensen I, Petersen LC and Kluft C: Purification and characterization of a novel, oligomeric, plasminogen kringle 4 binding protein from human plasma: Tetranectin. Eur J Biochem 156: 327-333, 1986.

10. Wewer UM, Ibaraki K, Schjørring P, Durkin ME, Young MF and Albrechtsen R: A potential role for tetranectin in mineralization during osteogenesis. J Cell Biol 127: 1767-1775, 1994.

11. Wewer UM, Iba K, Durkin ME, Nielsen FC, Loechel F, Gilpin BJ, Kuang W, Engvall E and Albrechtsen R: Tetranectin is a novel marker for myogenesis during embryonic development, muscle regeneration, and muscle cell differentiation in vitro. Dev Biol 200: 247-259, 1998.

12. Yin X, Subramanian S, Hwang SJ, O'Donnell CJ, Fox CS, Courchesne P, Muntendam P, Gordon N, Adourian A, Juhasz $\mathrm{P}$, et al: Protein biomarkers of new-onset cardiovascular disease: Prospective study from the systems approach to biomarker research in cardiovascular disease initiative. Arterioscler Thromb Vasc Biol 34: 939-945, 2014.

13. Chen Y, Han H, Yan X, Ding F, Su X, Wang H, Chen Q, Lu L, Zhang R and Jin W: Tetranectin as a potential biomarker for stable coronary artery disease. Sci Rep 5: 17632, 2015.

14. Chen Z, Wang E, Hu R, Sun Y, Zhang L, Jiang J, Zhang Y and Jiang H: Tetranectin gene deletion induces Parkinson's disease by enhancing neuronal apoptosis. Biochem Biophys Res Commun 468: 400-407, 2015.

15. Jensen BA and Clemmensen I: Plasma tetranectin is reduced in cancer and related to metastasia. Cancer 62: 869-872, 1988.

16. Nielsen H, Clemmensen I, Nielsen HJ and Drivsholm A: Decreased tetranectin in multiple myeloma. Am J Hematol 33: 142-144, 1990.

17. Høgdall CK, Høgdall EV, Hørding U, Daugaard S, Clemmensen I, Nørgaard-Pedersen B and Toftager-Larsen K: Plasma tetranectin and ovarian neoplasms. Gynecol Oncol 43: 103-107, 1991.

18. Høgdall CK, Christiansen M, Nørgaard-Pedersen B, Bentzen SM Kronborg O and Clemmensen I: Plasma tetranectin and colorectal cancer. Eur J Cancer 31A: 888-894, 1995.

19. Felix K, Hauck O, Fritz S, Hinz U, Schnölzer M, Kempf T, Warnken U, Michel A, Pawlita M and Werner J: Serum protein signatures differentiating autoimmune pancreatitis versus pancreatic cancer. PLoS One 8: e82755, 2013.

20. Lundstrøm MS, Høgdall CK, Nielsen AL and Nyholm HC: Serum tetranectin and CA125 in endometrial adenocarcinoma. Anticancer Res 20: 3903-3906, 2000.

21. Arellano-Garcia ME, Li R, Liu X, Xie Y, Yan X, Loo JA and $\mathrm{Hu}$ S: Identification of tetranectin as a potential biomarker for metastatic oral cancer. Int J Mol Sci 11: 3106-3121, 2010.

22. Høgdall CK, Hørding U,Nørgaard-Pedersen B, Toftager-Larsen K and Clemmensen I: Serum tetranectin and CA-125 used to monitor the course of treatment in ovarian cancer patients. Eur J Obstet Gynecol Reprod Biol 57: 175-178, 1994.

23. Chen H, Li H, Zhao J, Peng P, Shao M, Wu H, Wang X, Chen L, Zhang Q, Ruan Y, et al: High intratumoral expression of tetranectin associates with poor prognosis of patients with gastric cancer after gastrectomy. J Cancer 8: 3623-3630, 2017. 
24. Obrist P, Spizzo G, Ensinger C, Fong D, Brunhuber T, Schäfer G, Varga M, Margreiter R, Amberger A, Gastl G and Christiansen M: Aberrant tetranectin expression in human breast carcinomas as a predictor of survival. J Clin Pathol 57: 417-421, 2004.

25. Heeran MC, Rask L, Høgdall CK, Kjaer SK, Christensen L, Jensen A, Blaakaer J, Jarle Christensen IB and Høgdall EV: Tetranectin positive expression in tumour tissue leads to longer survival in Danish women with ovarian cancer. Results from the 'Malova' ovarian cancer study. APMIS 123: 401-409, 2015.

26. Mermel CH, Schumacher SE, Hill B, Meyerson ML, Beroukhim R and Getz G: GISTIC2.0 facilitates sensitive and confident localization of the targets of focal somatic copy-number alteration in human cancers. Genome Biol 12: R41, 2011.

27. Gao J, Aksoy BA, Dogrusoz U, Dresdner G, Gross B, Sumer SO, Sun Y, Jacobsen A, Sinha R, Larsson E, et al: Integrative analysis of complex cancer genomics and clinical profiles using the cBioPortal. Sci Signal 6: pl1, 2013.

28. Rhodes DR, Yu J, Shanker K, Deshpande N, Varambally R, Ghosh D, Barrette T, Pandey A and Chinnaiyan AM ONCOMINE: A cancer microarray database and integrated data-mining platform. Neoplasia 6: 1-6, 2004.

29. Song Y, Li L, Ou Y, Gao Z, Li E, Li X, Zhang W, Wang J, Xu L, Zhou Y, et al: Identification of genomic alterations in oesophageal squamous cell cancer. Nature 509: 91-95, 2014.

30. Ashburner M, Ball CA, Blake JA, Botstein D, Butler H, Cherry JM, Davis AP, Dolinski K, Dwight SS, Eppig JT, et al: Gene ontology: tool for the unification of biology. The Gene Ontology Consortium. Nat Genet 25: 25-29, 2000.

31. Huang dW, Sherman BT and Lempicki RA: Systematic and integrative analysis of large gene lists using DAVID bioinformatics resources. Nat Protoc 4: 44-57, 2009.

32. Lam JS, Klatte T and Breda A: Staging of renal cell carcinoma: Current concepts. Indian J Urol 25: 446-454, 2009.

33. Moch $\mathrm{H}$ : The WHO/ISUP grading system for renal carcinoma. Pathologe 37: 355-360, 2016 (In German).

34. Beroukhim R, Brunet JP, Di Napoli A, Mertz KD, Seeley A, Pires MM, Linhart D, Worrell RA, Moch H, Rubin MA, et al: Patterns of gene expression and copy-number alterations in von-hippel lindau disease-associated and sporadic clear cell carcinoma of the kidney. Cancer Res 69: 4674-4681, 2009.

35. Macé A, Kutalik Z and Valsesia A: Copy number variation. Methods Mol Biol 1793: 231-258, 2018.

36. Nickerson ML, Jaeger E, Shi Y, Durocher JA, Mahurkar S, Zaridze D, Matveev V, Janout V, Kollarova H, Bencko V, et al: Improved identification of von Hippel-Lindau gene alterations in clear cell renal tumors. Clin Cancer Res 14: 4726-4734, 2008.

37. Zhang W and Liu HT: MAPK signal pathways in the regulation of cell proliferation in mammalian cells. Cell Res 12:9-18, 2002.

38. van Dam S, Võsa U, van der Graaf A, Franke L and de Magalhães J: Gene co-expression analysis for functional classification and gene-disease predictions. Brief Bioinform: 2017.

39. Cecchi F, Rabe DC and Bottaro DP: Targeting the HGF/Met signalling pathway in cancer. Eur J Cancer 46: 1260-1270, 2010.

40. Justilien V, Ali SA, Jamieson L, Yin N, Cox AD, Der CJ, Murray NR and Fields AP: Ect2-dependent rRNA synthesis is required for KRAS-TRP53-driven lung adenocarcinoma. Cancer Cell 31: 256-269, 2017.

41. Bracken AP, Pasini D, Capra M, Prosperini E, Colli E and Helin K: EZH2 is downstream of the pRB-E2F pathway, essential for proliferation and amplified in cancer. EMBO J 22: 5323-5335, 2003.
42. Ryu S and Driever W: Minichromosome maintenance proteins as markers for proliferation zones during embryogenesis. Cell Cycle 5: 1140-1142, 2006.

43. Guo Y, Xie J, Rubin E, Tang YX, Lin F, Zi X and Hoang BH: Frzb, a secreted Wnt antagonist, decreases growth and invasiveness of fibrosarcoma cells associated with inhibition of Met signaling. Cancer Res 68: 3350-3360, 2008.

44. Andreeva AV and Kutuzov MA: Cadherin 13 in cancer. Genes Chromosomes Cancer 49: 775-790, 2010.

45. Liu X, Lan Y, Zhang D, Wang K, Wang Y and Hua ZC: SPRY1 promotes the degradation of uPAR and inhibits uPAR-mediated cell adhesion and proliferation. Am J Cancer Res 4: 683-697. 2014.

46. Oh KY, Hong KO, Huh YS, Lee JI and Hong SD: Decreased expression of SOX7 induces cell proliferation and invasion and correlates with poor prognosis in oral squamous cell carcinoma. J Oral Pathol Med 46: 752-758, 2017.

47. Jafri M, Wake NC, Ascher DB, Pires DE, Gentle D, Morris MR, Rattenberry E, Simpson MA, Trembath RC, Weber A, et al: Germline Mutations in the CDKN2B tumor suppressor gene predispose to renal cell carcinoma. Cancer Discov 5: 723-729, 2015.

48. Paz N, Levanon EY, Amariglio N, Heimberger AB, Ram Z, Constantini S, Barbash ZS, Adamsky K, Safran M, Hirschberg A, et al: Altered adenosine-to-inosine RNA editing in human cancer. Genome Res 17: 1586-1595, 2007.

49. Sánchez-Martín D, Otsuka A, Kabashima K, Ha T, Wang D, Qian X, Lowy DR and Tosato G: Effects of DLC1 deficiency on endothelial cell contact growth inhibition and angiosarcoma progression. J Natl Cancer Inst 110: 390-399, 2017.

50. Kim YM, Stone M, Hwang TH, Kim YG, Dunlevy JR, Griffin TJ and Kim DH: SH3BP4 is a negative regulator of amino acid-Rag GTPase-mTORC1 signaling. Mol Cell 46: 833-846, 2012.

51. Shen YJ, Kong ZL, Wan FN, Wang HK, Bian XJ, Gan HL, Wang CF and Ye DW: Downregulation of DAB2IP results in cell proliferation and invasion and contributes to unfavorable outcomes in bladder cancer. Cancer Sci 105: 704-712, 2014.

52. Høgdall CK, Christensen L and Clemmensen I: The prognostic value of tetranectin immunoreactivity and plasma tetranectin in patients with ovarian cancer. Cancer 72: 2415-2422, 1993.

53. Høgdall CK, Sölétormos G, Nielsen D, Nørgaard-Pedersen B, Dombernowsky P and Clemmensen I: Prognostic value of serum tetranectin in patients with metastatic breast cancer. Acta Oncol 32: 631-636, 1993.

54. Bamborough P, Chung CW, Demont EH, Furze RC, Bannister AJ, Che KH, Diallo H, Douault C, Grandi P, Kouzarides T, et al: A Chemical probe for the ATAD2 bromodomain. Angew Chem Int Ed Engl 55: 11382-11386, 2016.

55. Saha A, Kim Y, Gewirtz ADH, Jo B, Gao C, McDowell IC; GTEx Consortium, Engelhardt BE and Battle A: Co-expression networks reveal the tissue-specific regulation of transcription and splicing. Genome Res 27: 1843-1858, 2017.

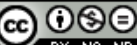

This work is licensed under a Creative Commons Attribution-NonCommercial-NoDerivatives 4.0 International (CC BY-NC-ND 4.0) License. 